\section{Post-Operative Prevention of Venous Thromboembolism in Hip and Knee Arthroplasty Surgery: A Study of the Combined Use of Low Molecular Weight Heparin and Rivaroxaban}

\section{Oisin Breathnach*, Eszter Karip, Gerald McCoy, May Cleary and John Quinlan}

Lourdes Orthopaedic Hospital, Kilcreene, Kilkenny, Republic of Ireland

\begin{abstract}
Introduction

Venous Thromboembolism (VTE) is an issue of substantial concern in Orthopaedic Surgery. Despite developments in its detection and treatment, death rates from VTE remain an issue of concern. Factor $\mathrm{Xa}$ inhibition is the latest method of anti-coagulation and is being marketed as a successor to the use of - Low Molecular Weight Heparin (LMWH). This review cohort study investigates the use of factor Xa inhibitors and its combined use with LMWH.

\section{Methods}

Patients who had undergone primary Total Hip Arthroplasty (THA) or Total Knee Arthroplasty (TKA) were recruited for this retrospective study. Patients were divided in to two groups. Group day 1 were administered LMWH (Clexane ${ }^{\circledR} 40 \mathrm{mg}$ ) subcutaneously on the day of surgery and rivaroxaban (Xarelto ${ }^{\circledR}$ ) was given on day 1 post THA/TKA. Group day 3 were administered LMWH (Clexane ${ }^{\circledR} 40$ $\mathrm{mg}$ ) subcutaneously for three days post THA/TKA. This included administration of LMWH on day of surgery. Rivaroxaban (Xarelto ${ }^{\circledR}$ ) was administered therefore on day 3 post surgery. Rivaroxaban $\left(\right.$ Xarelto ${ }^{\circledR}$ ) was administered for six weeks in total post operation in both groups.

33 patients had met the appropriate criteria for inclusion the study but were subsequently excluded due to wound related issues while on rivaroxaban (Xarelto ${ }^{\circledR}$ ). The medication had been held for at least 48 hours.
\end{abstract}

*Corresponding author: Oisin Breathnach, Lourdes Orthopaedic Hospital Kilcreene, Kilkenny, Republic of Ireland, Tel: +353 0861003008; E-mail: opbreathnach@hotmail.com

Citation: Breathnach O, Karip E, McCoy G, Cleary M, Quinlan J (2016) Post-Operative Prevention of Venous Thromboembolism in Hip and Knee Arthroplasty Surgery: A Study of the Combined Use of Low Molecular Weight Heparin and Rivaroxaban. J Orthop Res Physiother 2: 020.

Received: 05, October 2015; Accepted: 27, January 2016; Published: 11, February 2016

\begin{abstract}
Results
The use of rivaroxaban (Xarelto ${ }^{\circledR}$ ) earlier in the post operative period is associated with higher rate of dressing change and earlier dressing change. The use of rivaroxaban (Xarelto ${ }^{\circledR}$ ) early in the prevention of VTE is also associated with an increased average total blood loss when compared with those using rivaroxaban (Xarelto $\left.{ }^{\circledR}\right)$ at a later stage $(p<0.001)$. Patients who received rivaroxaban $\left(\right.$ Xarelto $\left.^{\circledR}\right)$ directly post operation required more dressing changes (2.19) as opposed to 1.92 dressing changes in those patients who received rivaroxaban $\left(\right.$ Xarelto $\left.^{\circledR}\right)$ at a later stage $(p<0.01)$.

\section{Conclusion}

There are better clinical results when administering rivaroxaban (Xarelto ${ }^{\circledR}$ ) at day 3 post operation as described. Wound complications may be avoided if rivaroxaban (Xarelto ${ }^{\circledR}$ ) administration is delayed until the third post-operative day. The authors in this study have altered their practice in relation to the timing of rivaroxaban (Xarelto ${ }^{\circledR}$ ) administration. The use of rivaroxaban (Xarelto ${ }^{\circledR}$ ) will need to audited regularly in our unit as it is new method of anti-coagulation. Failure to complete a full treatment course of rivaroxaban (Xarelto ${ }^{\circledR}$ ) due to early wound complications in our THA/TKA will also inform any decisions on its long-term use.
\end{abstract}

\section{Introduction}

Venous Thromboembolism (VTE) is the term used to describe the formation of Deep Vein Thrombosis (DVT) followed by its frequent sequelae Pulmonary Embolism (PE). VTE is an issue of substantial concern in trauma and orthopaedic surgery. Death rates secondary to DVT among hospitalised patients have been reported in approximately $6 \%$ of all DVT cases [1]. In addition to increasing mortality, DVT also prolongs hospitalisation which leads to increased healthcare costs [2]. The valvular destruction associated with a dislodged thrombus leads to post-thrombotic chronic venous insufficiency in 30\% of cases as well as venous ulceration and the risk of recurrent DVT [3,4]. The incidence rates of DVT remain unacceptably high with rates as high as $30 \%$ in general surgical patients and $85 \%$ reported in orthopaedic patients without prophylaxis [5-8]. Improved methods of reporting and imaging has assisted early diagnosis of DVT amongst health professionals [9].

Virchow described the pathogenesis of DVT as a triad of factors: (i) alterations in the blood constitution or hypercoagulability, (ii) alterations in blood flow or venous stasis and (iii) vascular endothelial damage [10-12]. Anticoagulants are administered to interrupt the potential hypercoagulabilty in post-operative arthroplasty patients. Mechanical devices are sometimes administered in conjunction with anticoagulants for higher risk patients, or in place of anticoagulants in situations where anticoagulants are contraindicated [8].

The most common oral anticoagulant available is warfarin. It is widely prescribed as a first line anticoagulant in conditions such as atrial fibrilliation. Its previous uses include as a prevention tool for DVT in post-operative arthroplasty patients. Parenteral medications such as Low-Molecular-Weight Heparin (LMWH) have been more recently used to prevent post-operative DVT. Second-generation LMWH with the lowest molecular weight, the longest half-life and the highest anti-Factor Xa/anti-Factor IIa activity ratio-it can be safely used in special categories of patients (children, elderly, patients with 
renal impairment and congestive heart failure) [13]. Aspirin has also been advocated in terms of reducing postoperative DVT rates [14].

Direct factor Xa inhibition in the clotting cascade is the latest attempt to help reduce VTE. Rivaroxaban (Xarelto ${ }^{\circ}$-Bayer AG, Leverkusen, Germany) is the factor Xa inhibitor used as part of this study. It is recommended to be given as a $10 \mathrm{mg}$ tablet once daily over differing time periods for THA and TKA. It is to be administered with caution in patients with poor creatinine clearance [15].

The use of an oral anti-coagulant which is deemed to be both safe and beneficial to patients would provide for a major change in ths treatment and prevention of VTE. Post-operatively the first aim should be to prevent VTE. Recent use of Xa inhibitors would indicate that its use is quiet favourable when used to prevent VTE in post operative patients in comparison to other anti-coagulants [15]. Xa inhibitors are also being advocated for patients as its use does not have to monitored by means of blood test nor is there the discomfort of sub-cutaneous injection therapy.

\section{Objective}

The hypothesis of this study is that the use of rivaroxaban $\left(\right.$ Xarelto $\left.^{\circ}\right)$ is a suitable method of anticoagulation in patients post hip and knee arthroplasty. The main objective is:

To determine the most suitable protocol of administration of rivaroxaban $\left(\right.$ Xarelto $\left.^{\circ}\right)$ for the patient population in the observed patient cohort.

\section{Patients and Methods}

Consecutive patients who had undergone primary Total Hip Arthroplasty (THA) or Total Knee Arthroplasty (TKA) in our institution were recruited for this study. All surgeries were carried out by or under the direct scrubbed supervision of 6 consultant grade surgeons. This study was deemed exempt from formal ethical approval following an application to the local ethical committee review group. Exclusion criteria for patients included:

1. Patients on Warfarin pre-arthroplasty surgery.

2. Revision surgery.

3. Unicompartmental knee replacement.

4. Patients who had rivaroxaban (Xarelto ${ }^{\circ}$ ) held for more than forty-eight hours or more due to wound related issues.

\section{Patient groups}

The rivaroxaban $\left(\right.$ Xarelto $\left.^{\circ}\right)$ dosing recommendations allow for the use of LMWH in combination. Rivaroxaban (Xarelto ${ }^{\circ}$ ) may be given in place of LMWH provided that it is given 0 to 2 hours prior to the time of the next scheduled administration of LMWH [13]. The recommendations also state that rivaroxaban $\left(\right.$ Xarelto $\left.^{\circ}\right)$ may be commenced 6 to 10 hours after surgery provide that haemostasis has been established. LMWH (Clexane $40 \mathrm{mg}$ ) was administered six hours post completion of surgery in each case. Rivaroxaban (Xarelto $\left.{ }^{\circ}\right)$ was administered for six weeks in total post operation in both groups.

These recommendations therefore allowed for the creation of two different treatment protocols:

1. Group day 1 were administered LMWH (Clexane $40 \mathrm{mg}-\mathrm{Sa}-$ nofi-Aventis, NJ, USA.) subcutaneously on the day of surgery. Rivaroxaban $\left(\right.$ Xarelto $^{\circ}$ ) was administered on day one post THA/TKA.
2. Group day 3 were administered LMWH (Clexane $40 \mathrm{mg}$ ) subcutaneously for three days post THA/TKA. This included administration of LMWH on day of surgery. Rivaroxaban $\left(\right.$ Xarelto $^{\oplus}$ ) was administered therefore on day 3 post surgery.

Patients were followed in these two comparative cohort groups. This study looks retrospectively at the two patient groups into which patients were enrolled contemporaneously as per the preferences of each individual consultant surgeon. Five hundred and fifty six patients were initially included in this study of which 147 were excluded based on the criteria outlined previously.

The following outcome measures were assessed:

1. The day of first dressing change. A standard Jubilee (Convatec UK, Middlesex, United Kingdom) dressing was applied to all patients.

2. The number of dressing changes.

3. The total blood loss.

Statistical analysis was performed using Analysis of Variance techniques (ANOVA) from the Microsoft Excel programme (Microsoft Corporation, Seattle WA, USA). Statistical significance was taken for all values of $\mathrm{p} \leq 0.05$.

\section{Results}

Four hundred and nine consecutive patients were included in this study of which 241 were allocated to the day 1 group comprising 131 THA and 110 TKA. One hundred and sixty eight patients were allocated to the day 3 group with 87 THA and 81 TKA. The average age was 66.4 for all patient groups inclusive.

\section{Dressing change}

Standard post-operative protocol in the reporting institution involves a standard dressing change which takes place on all THA/TKA patients on day 5. A Jubilee dressing has been applied on all wounds following arthroplasty cases based on its associated low complication rate which has been confirmed by means of randomised controlled trial [16]. Both patient groups required early a dressing change; day 1 group at 2.41 days and day 3 group at 2.37 days. The difference between the 2 groups was not significant. However, the day 1 group required more dressing changes (2.19) as opposed to 1.92 dressing changes for the day 3 group. This was found to statistically significant $(\mathrm{p}<0.01)$ (Figure 1$)$

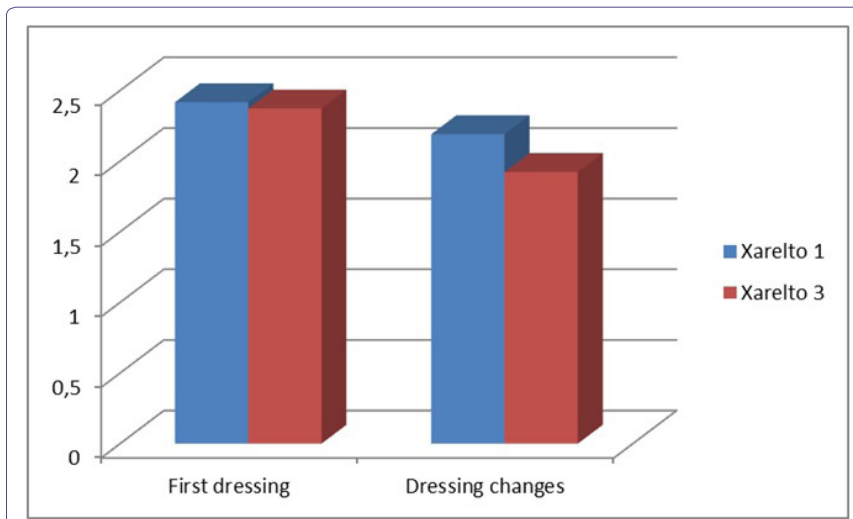

Figure 1: Day of first dressing/number of dressing changes.

\section{Blood loss}

Blood loss was calculated following assessment of drain contents and wound dressing measurement. In the day 1 group 200 patients 
(total 241) had drains inserted. In the day 3 group 47 patients had drains inserted (total 168). The total average blood loss was found to be $605 \mathrm{mls}$ and $340 \mathrm{mls}$ in the day 1 group and day 3 group respectively $(\mathrm{p}<0.001)$. The trend of higher blood loss with those in the day 1 group in comparison with the day 3 group was also observed when patients without drains were analysed $-265 \mathrm{mls}$ and $220 \mathrm{mls}$ in the day 1 and day 3 groups respectively.

\section{Limitations}

Overall, 147 patients were excluded as part of this study. Initially, however, 33 patients had met the appropriate criteria for inclusion the study but were subsequently excluded due to wound related issues while on rivaroxaban (Xarelto ${ }^{\circ}$ ). The medication had been held for at least 48 hours. 24 of these patients had been part of the day 1 group whilst 9 patients were part of the day 3 group. The authors acknowledge that there is a significant number of patients excluded at this point of the study. These patients were excluded in order to compare a full treatment protocol of rivaroxaban (Xarelto ${ }^{\circ}$ ) and early administration of LMWH (Clexane ${ }^{\oplus} 40 \mathrm{mg}$ ).

The review of patients in this study was retrospective in nature. The comparative groups were created based on surgeon preference for the use rivaroxaban $\left(\mathrm{Xarelto}^{\circ}\right.$ ) in the post-operative setting.

\section{Discussion}

Multiple therapies have contributed to the reduction in VTE in post-operative THA and TKA. Factor Xa inhibitors such as rivaroxaban $\left(\mathrm{Xarelto}^{\circ}\right)$ have become well established in orthopaedic practice following the publication of the RECORD studies [17]. Despite the reported results in reduced VTE the changeover to oral factor Xa inhibitors has not been universal. Concerns have been expressed in relation to post-operative bleeding and subsequent wound complications [18]. Jameson et al., prospectively collected data on 2762 patients who were administered rivaroxaban (Xarelto ${ }^{\circ}$ ) post THA/TKA and found that there were more likely to have wound complications at 30 days than over 10,000 patients administered LMWH. Jensen et al., also reports retrospectively on 1048 THA/TKA patients equally divided to receive either LMWH or rivaroxaban $\left(\right.$ Xarelto $\left.^{\circ}\right) 10 \mathrm{mg}$ as part of their post-operative treatment [19]. During the first 30 days post-operation $9(1.8 \%)$ of the LMWH group returned to theatre for irrigation and drainage compared to $22(3.94 \%)$ in the rivaroxaban (Xarelto ${ }^{\circ}$ ) groups.

The results produced in our study also indicate that there is greater need to change dressings and a higher rate of blood loss in that patient group that commenced rivaroxaban $\left(\mathrm{Xarelto}^{\circ}\right)$ on day 1 post-operation compared to those who have delayed administration of the drug. There is clear evidence from this study that early administration of rivaroxaban (Xarelto ${ }^{\circ}$ ) leads to an increased amount of wound haemorrhage when compared to the delayed administration of the medication. In order to reduce the risk of post-operative wound complications such as haematoma and infection we believe that a modified approach to the use of rivaroxaban (Xarelto ${ }^{\circ}$ ) in conjunction with LMWH is appropriate. It has been acknowledged that the American College of Chest Physicians (ACCP) and the American Academy of Orthopaedic Surgeons (AAOS) have adopted new guidelines which allow for varied pharmacological prophylaxis $[20,21]$. The AAOS guidelines allow the surgeon increased autonomy to choose suitable anti-VTE prophylaxis based primarily on clinical judgment. The AAOS advocate early engagement with the patient in relation to post-operative prophylaxis, the risks and benefits of treatment and also discussion in relation the length of treatment post-operation.

During this review 33 patients initially included in the study were excluded due to the fact that rivaroxaban $\left(\mathrm{Xarelto}^{\circ}\right.$ ) was held for 48 hours. The medication was held due to the fact that there was wound haemorrhage. The authors have suggested that a day 3 administration of rivaroxaban $\left(\right.$ Xarelto $\left.^{\circ}\right)$ is more appropriate in terms of wound management. 24 of the 33 patients who were excluded were given rivaroxaban $\left(\mathrm{Xarelto}^{\circ}\right)$ at day 1 . Despite these patients being excluded from our results it does support the finding of wound haemorrhage when rivaroxaban (Xarelto ${ }^{\circ}$ ) is administered early. As a result of the findings, all of the surgeons involved in the study have changed their practice to the day 3 protocol.

A number of concerns have been expressed in relation to the use of rivaroxaban $\left(\mathrm{Xarelto}^{\circ}\right)$. These concerns include economic and also concerns related to the direct side effects of the medication. A review of the use of the medication in the German healthcare system reflected positively on rivaroxaban (Xarelto ${ }^{\circ}$ ) from a cost perspective. The decreased rate of VTE in TKA when patients are treated with rivaroxaban $\left(\right.$ Xarelto $\left.^{\circ}\right)$ indicated a saving of $€ 27.3$ per patient treated [22]. This figure makes allowances for VTE events that would be avoided when rivaroxaban $\left(X_{\text {Xarelto }}{ }^{\circ}\right)$ is administered. A LMWH was also given over the same time period as that of rivaroxaban $\left(\right.$ Xarelto $^{\circ}$ ) (32 days for THA and 13 days for TKA). The use of a LMWH post discharge from hospital would not be standard practice in all THA/TKA. The use of a LMWH and its associated cost over a longer timeframe in this study might therefore alter the cost base analysis. However, the authors believe that a long term view of the positive results of rivaroxaban $\left(\mathrm{Xarelto}^{\circ}\right)$ in relation to VTE treatment should be taken when considering cost concerns. Case reports [23] published in the literature in relation to rivaroxaban (Xarelto ${ }^{\circ}$ ) cannot be ignored. However the risk of gasto-intestinal haemorrhage is a recognised side effect of most if not all anti-VTE medication. The AAOS recommend therefore that each patient should be counselled in relation to the most appropriate anti-VTE medication to be used in order to explain the potential risks and benefits of each medication [21]. The authors in this study have altered their practice in relation to the timing of rivaroxaban $\left(\mathrm{Xarelto}^{\circ}\right)$ administration. The use of rivaroxaban $\left(\mathrm{Xarelto}^{\oplus}\right)$ in all patients will continue.

\section{Conclusion}

There are better clinical results when administering rivaroxaban $\left(\mathrm{Xarelto}^{\circ}\right)$ at day 3 post operation as described. Wound complications may be avoided if rivaroxaban (Xarelto ${ }^{\circ}$ ) administration is delayed until the third post-operative day. The authors in this study have altered their practice in relation to the timing of rivaroxaban (Xarelto ${ }^{\circ}$ ) administration. The use of rivaroxaban (Xarelto ${ }^{\circ}$ ) will need to audited regularly in our unit as it is new method of anti-coagulation. Failure to complete a full treatment course of rivaroxaban (Xarelto ${ }^{\circ}$ ) due to early wound complications in our THA/TKA will also inform any decisions on its long-term use.

\section{References}

1. White RH (2003) The epidemiology of venous thromboembolism. Circulation 107: 4-8.

2. Illingworth C, Timmons S (2007) An audit of Intermittent Pneumatic Compression (IPC) in the prophylaxis of asymptomatic Deep Vein Thrombosis (DVT). J Perioper Pract 17: 522-524, 526-528.

3. MacLellan DG, Fletcher JP (2007) Mechanical compression in the prophylaxis of venous thromboembolism. ANZ J Surg 77: 418-423. 
Citation: Breathnach O, Karip E, McCoy G, Cleary M, Quinlan J (2016) Post-Operative Prevention of Venous Thromboembolism in Hip and Knee Arthroplasty Surgery: A Study of the Combined Use of Low Molecular Weight Heparin and Rivaroxaban. J Orthop Res Physiother 2: 020.

4. Prandoni $P$, Lensing AW, Prins MR (1998) Long-term outcomes after deep venous thrombosis of the lower extremities. Vasc Med 3: 57-60.

5. Autar R (2007) NICE guidelines on reducing the risk of venous thromboembolism (deep vein thrombosis and pulmonary embolism) in patients undergoing surgery. Journal of Orthopaedic Nursing 11: 169-176.

6. O'Neill MJ (2001) Developing a clinically effective DVT prophylaxis protocol. Journal of Orthopaedic Nursing 5: 186-191.

7. Arnold DM, Kahn SR, Shrier I (2001) Missed opportunities for prevention of venous thromboembolism: an evaluation of the use of thromboprophylaxis guidelines. Chest 120: 1964-1971.

8. Geerts WH, Pineo GF, Heit JA, Bergqvist D, Lassen MR, et al. (2004) Prevention of venous thromboembolism: the Seventh ACCP Conference on Antithrombotic and Thrombolytic Therapy. Chest 126: 338-400.

9. Galeandro Al, Quistelli G, Scicchitano P, Gesualdo M, Zito A, et al. (2012) Doppler ultrasound venous mapping of the lower limbs. Vasc Health Risk Manag 8: 59-64.

10. Anning ST (1957) The historical aspects of venous thrombosis. Med Hist 1: 28-37.

11. Virchow $R$ (1846) Uber die Vertpfung der Lungenarterie. Neue Notizen und Geb d Natur Heilk 36: 26.

12. Schafer Al (2007) Hypercoagulable state. In: Willerson JT, Wellens HJJ, Cohn JN, Holmes DR Jr. (eds.). Cardiovascular Medicine. (3rdedn), Springer, Germany. Pg no: 2423-2428.

13. Ciccone MM, Cortese F, Corbo F, Corrales NE, Al-Momen AK, et al. (2014) Bemiparin, an effective and safe low molecular weight heparin: a review. Vascul Pharmacol 62: 32-37.

14. [No authors listed] (1994) Collaborative overview of randomised trials of antiplatelet therapy--III: Reduction in venous thrombosis and pulmonary embolism by antiplatelet prophylaxis among surgical and medical patients. Antiplatelet Trialists' Collaboration. BMJ 308: 235-246.
15. Xarelto ${ }^{\circledR}$ (rivaroxaban) 10mg [summary of product characteristics].

16. Burke NG, Green C, McHugh G, McGolderick N, Kilcoyne C, et al. (2012) A prospective randomised study comparing the jubilee dressing method to a standard adhesive dressing for total hip and knee replacements. J Tissue Viability $21: 84-87$.

17. Eriksson BI, Kakkar AK, Turpie AG, Gent M, Bandel TJ, et al. (2009) Oral rivaroxaban for the prevention of symptomatic venous thromboembolism after elective hip and knee replacement. J Bone Joint Surg Br 91: 636-644.

18. Jameson SS, Rymaszewska M, Hui AC, James P, Serrano-Pedraza I, et al (2012) Wound complications following rivaroxaban administration: a multicenter comparison with low-molecular-weight heparins for thromboprophylaxis in lower limb arthroplasty. J Bone Joint Surg Am 94: 1554-1558.

19. Jensen CD, Steval A, Partington PF, Reed MR, Muller SD (2011) Return to theatre following total hip and knee replacement, before and after the introduction of rivaroxaban: a retrospective cohort study. J Bone Joint Surg $\mathrm{Br}$ 93: 91-95.

20. Falck-Ytter Y, Francis CW, Johanson NA, Curley C, Dahl OE (2012) Prevention of VTE in orthopedic surgery patients: antithrombotic therapy and prevention of thrombosis, 9th ed: American College of Chest Physicians evidence-based clinical practice guidelines. Chest 141: 278-325

21. Mont MA, Jacobs JJ, Boggio LN, Bozic KJ, Della Valle CJ (2011) Preventing venous thromboembolic disease in patients undergoing elective hip and knee arthroplasty. J Am Acad Orthop Surg 19: 768-776.

22. Zindel S, Stock S, Müller D, Stollenwerk B (2012) A multi-perspective cost-effectiveness analysis comparing rivaroxaban with enoxaparin sodium for thromboprophylaxis after total hip and knee replacement in the German healthcare setting. BMC Health Serv Res 12: 192

23. Boland M, Murphy M, Murphy M, McDermott E (2012) Acute-onset severe gastrointestinal tract hemorrhage in a postoperative patient taking rivaroxaban after total hip arthroplasty: a case report. J Med Case Rep 6: 129. 